\title{
Which physiological parameters are associated with rowing performance?
}

\section{ELITE SPORTS

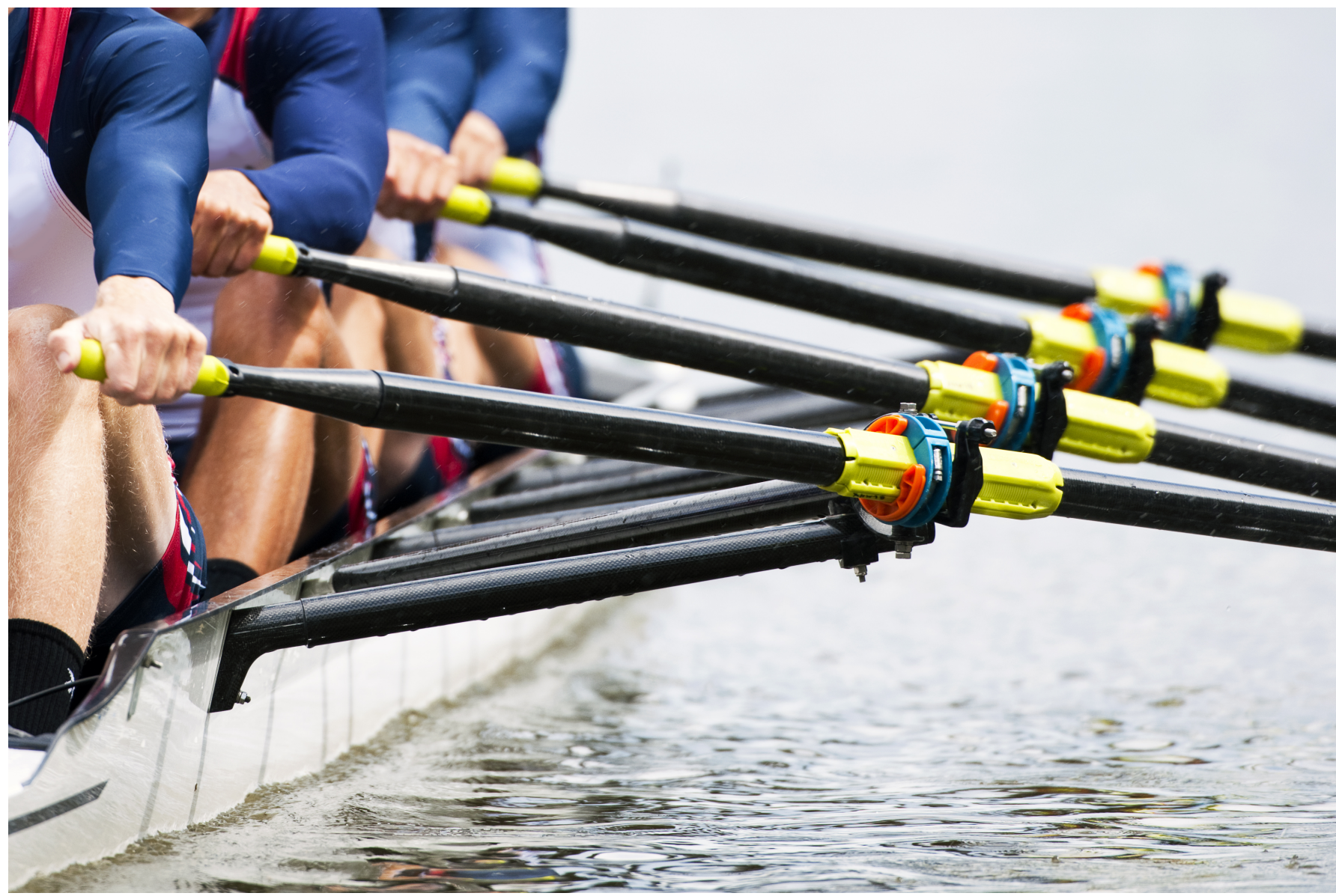

Otter-Kaufmann $\mathbf{L}^{1}$, Hilfiker $\mathbf{R}^{2}$, Ziltener $J-\mathbf{L}^{3}$, Allet $\mathbf{L}^{4}$

${ }^{1}$ Bern University of Applied Sciences, Health Division, Discipline of Physiotherapy, Bern, Switzerland

${ }^{2}$ University of Applied Sciences and Arts of Western Switzerland Valais, Physiotherapy, Switzerland

${ }^{3}$ Centre de médecine du sport et de l'exercice, La Colline, Geneva, Switzerland

${ }^{4}$ University of Applied Sciences of Western Switzerland, Physiotherapy, Switzerland; Department of Community Medicine, University Hospitals and University of Geneva, Geneva, Switzerland 


\section{Abstract}

This observational study used field tests to investigate the association between physiological parameters and rowing performance in athletes during ergometer and on-water Swiss national competitions. 25 Participants between 15 and 35 years who compete at national level were recruited among different clubs. We assessed anthropometric parameters such as weight, height, aerobic capacity during an incremental test on a rowing ergometer, anaerobic capacity during an on rowing ergometer Wingate test and lower limb strength and power during countermovement- and squat jumps. We took as performance measurements the results from two on-ergometer and two on-water rowing races. 25 rowers (age $17.4 \pm 2.4$ years), 6 women and 19 men participated in this study. We found very high to moderate correlations between on-ergometer performance and aerobic capacity $(r=0.91)$, anaerobic capacity $(r=0.78)$ and lower limb strength and power $(r=0.83 ; r=0.73)$ as well as moderate correlations between on-water performance and aerobic capacity $(r=0.63)$, anaerobic capacity $(r=0.60)$ and lower limb strength and power $(r=0.54$; $r=0.64)$. This study present descriptive performance reference values of elite Swiss rowers. Field tests are indicators of specific performance but more extensive studies would confirm the associations, notably according to the competition type. Once confirmed, the different strength of correlations between physiological parameters and rowing performances might be helpful in the near future to better adapt rowers' training preparation and athletes' selection for an elite team.

\section{Zusammenfassung}

Diese Studie untersuchte anhand von Feldtests den Zusammenhang zwischen physiologischen Parametern und der Ruderleistung bei Sportlern. Fünfundzwanzig Teilnehmer zwischen 15 und 35 Jahren, die an nationalen Ruderergometer- und klassischen Ruderwettbewerben teilnahmen wurden in die Studie eingeschlossen. Die Ruderer wurden aus verschiedenen Vereinen in der Schweiz rekrutiert. Gewicht und Körpergrösse wurden erhoben und die aerobe Kapazität während eines inkrementellen Tests und die anaerobe Kapazität während eines «Wingate-Tests» auf einem Ruderergometer gemessen. Zusätzlich wurde die Muskelkraft und Muskelleistung der unteren Extremitäten mittels Sprüngen mit und ohne Ausholbewegungen (countermovement jump und squat jump Test) erhoben. Die Ruderleistung wurde anhand der Ergebnisse von zwei Ruderergometer- und zwei klassischen Ruderrennen gemessen. Fünfundzwanzig Ruderer (Alter 17,4 \pm 2,4 Jahre), 6 Frauen und 19 Männer, nahmen an dieser Studie teil. Wir fanden moderate bis sehr hohe Korrelationen zwischen der Ergometer Wettkampfruderleistung und der aeroben Kapazität $(r=0,91)$, der anaeroben Kapazität $(r=0,78)$ und der Muskelkraft und Muskelleistung der unteren Extremitäten ( $r=0,83 ; r=0,73)$ sowie moderate Korrelationen zwischen der klassischen «On-water» Wettkampfruderleistung und der aeroben Kapazität $(r=0,63)$, der anaeroben Kapazität ( $r=0,60)$ und der Muskelkraft und Muskelleistung der unteren Extremitäten $(r=0,54 ; r=0,64)$. Diese Studie präsentiert deskriptive Leistungsreferenzwerte von Elite-Ruderern aus der Schweiz. Wir konnten zeigen, dass die gewählten Feldtests gute Indikatoren für die Ruderwettkampfleistung eines Athleten sind. Ausführlichere Studien sollten diese Zusammenhänge noch bestätigen und insbesondere relevante Indikatoren entsprechend der Art des Wettbewerbs (klassisch oder Ergometer) genauer untersuchen. Diese Ergebnisse können in Zukunft hilfreich sein, um die Trainingsvorbereitung der Ruderer zu optimieren und das Auswahlverfahren der Athleten für ein Elite-Team gezielter zu gestalten. 


\section{Introduction}

Identification of key parameters for good rowing performance is important for optimal planning and adaptation of rowing training, as well as for the selection procedures of athletes for elite teams [1,2]. For on-ergometer performance, these key parameters are aerobic and anaerobic power, as well as lower limb strength and power [1-4]. However, on-ergometer performance does not reflect the reality of on-water competitions [5]. As far as we know, no study measures the association from these four parameters with on-water performance. Furthermore, different available articles on this topic show various methodological limitations. Existing articles mainly include well experienced and trained young elite men and measure them on an ergometer during a laboratory trial, which reduces the generalizability of their results on a gender mix sample with a larger age span like the one of Swiss rowers at the national level (15 to 35 years old, gender mix) [2,3,6]. Moreover, measurements from physiological capacities are mainly done using instrumented tests in a laboratory setting. Such tests are difficult to realize in a rowing club due to the lack of equipment. Rowers or clubs are often not willing or able to organise tests in a laboratory due to time and budget constraints [3]. All these limitations make the identification of the most relevant factors for good on-water rowing performance difficult.

Therefore, the aim of this study is to investigate the association between key physiological parameters and rowing performance of athletes during a) on-ergometer and b) on-water Swiss national competitions using field tests. We further want to assess if this association depends on the competition type (on-water versus on-ergometer). We hypothesize that aerobic capacity will show the strongest positive association with both rowing performances, followed by the anaerobic capacity [7,8]. This study also wants to provide reference values of Swiss national rowers.

\begin{tabular}{|c|c|c|c|}
\hline & Performance/parameter & Test(s) & Outcomes \\
\hline & $\begin{array}{l}\text { On-ergometer rowing } \\
\text { performance }\end{array}$ & $\begin{array}{l}\text { Time results for } 1500 \mathrm{~m} \text { (U17) or } 2000 \mathrm{~m} \\
\text { (all other categories) respectively in two } \\
\text { competitions }\end{array}$ & Time lin s) \\
\hline & $\begin{array}{l}\text { On-water rowing perfor- } \\
\text { mance }\end{array}$ & $\begin{array}{l}\text { Time results for } 1500 \mathrm{~m} \text { (U17) or } 2000 \mathrm{~m} \\
\text { (all other categories) in single and } \\
\text { double sculls and coxless pair at two } \\
\text { national rowing races }\end{array}$ & Time lin s] \\
\hline \multirow[t]{2}{*}{ Primary outcomes } & Aerobic capacity & Incremental test on a rowing ergometer & $\begin{array}{l}\text { Maximal aerobic power } \\
\text { (in W) }\end{array}$ \\
\hline & Anaerobic capacity & Wingate test on a rowing ergometer & $\begin{array}{l}30 \text { seconds mean power } \\
\text { (in W) }\end{array}$ \\
\hline Secondary outcomes & $\begin{array}{l}\text { Lower limb: power and } \\
\text { strength }\end{array}$ & $\begin{array}{l}\text { Squat and counter movement jump } \\
\text { using an accelerometer }\end{array}$ & $\begin{array}{l}\text { Maximal Strength (in N) } \\
\text { Maximal Power [in W] }\end{array}$ \\
\hline Others outcomes & $\begin{array}{l}\text { Anthropometric parameters: } \\
\text { weight, height } \\
\text { Rowing experience and } \\
\text { rowing training description }\end{array}$ & & \\
\hline
\end{tabular}




\section{Methods}

\section{Participants}

We recruited 25 competitive rowers, men and women, from Clubs of the "Association Romande d'Aviron" (ARA). In order to have a representative sample of Swiss competitors at the national level, included rowers had to be between 15 and 35 years old with a minimum of 1 year of competition experience and to plan to compete in categories U17 (younger than 17 years), U19 (younger than 19 years) or senior (no age limitation) in national rowing competitions during the rowing season 2017.

\section{Design and ethical aspects}

This observational field study was approved by the Ethics Committee of Geneva (Trial number: 2015-00210 (15-299») and all participants signed the informed consent. For participants younger than 18 years old, their parents were asked to sign the informed consent.

\section{Testing procedure}

The testing procedure is illustrated in table 1 (competitions results published on http://www.swissrowing.ch/de/medien). An on-ergometer competition is a simulated race on a rowing ergometer [9,10]. All tests and competitions were done on Concept 2 ergometer (Concept II, Morrisville, VT, USA). Two on-ergometer competitions which took place in January and May 2017 were retained for statistical analysis. For rowers who did not attempt at least one of those two competitions, their last available ergometer performance (maximum 2 months before the testing procedure) in presence of their trainer or coach was retained for statistical analysis. For the on-water performance, only races with a team of one and two rowers at two competitions which occurred in April and May 2017 were consulted. Physiological parameters were assessed directly in the different rowing clubs between February and April 2017 by a trained assessor. Participants were asked not to do intensive exercises 24 hours (h) before the tests and not to consume alcohol or any stimulating drug and not to drink stimulating substances $3 \mathrm{~h}$ before the test [1]. During this session, participants were asked to fill in self-reported questionnaires about their rowing experience and their training program. Thereafter, the assessor assessed the participants' height and weight.

After a warm-up of 5 minutes (min), participants had time to get familiarized with the tests. Participants performed first lower limb strength and power tests, then an anaerobic test and finally aerobic capacity test. A 2 to 10 min regeneration period was respected between attempts as well as between tests. Between the Wingate test and aerobic assessment the regeneration period was $10 \mathrm{~min}$ and between both Wingate test attempts, 5 min.

In order to test lower limb strength and power, both squat- (SJ) and counter movement jumps (CMJ) [11] were performed five times each using an accelerometer device, the Myotest Pro 2 system (Myotest Pro 2 system, Myotest SA, Sion, Switzerland). Maximal strength (in Newton 〈N`) and maximal power (in Watt (W) were extracted.

Anaerobic capacity was measured by the 30 seconds mean power (in W) obtained during a $30 \mathrm{~s}$ all-out Wingate test on a rowing ergometer [2,12] which was performed twice. The resistance factor was set on 120. Participants were asked to row $30 \mathrm{~s}$ as fast as possible.

Aerobic capacity was measured during a unique incremental test on a Concept 2 rowing ergometer [9] and 
expressed as maximal aerobic power (MAP) (in W) [13]. A start power was assigned based on the results of participants' last ergometer performance (40,100 or $200 \mathrm{~W}$ ). This allowed us to set a specific test duration which ranged between 4 and $15 \mathrm{~min}$. The resistance factor was set at 120. Rowers were asked to increase their power from $20 \mathrm{~W}$ each minute until exhaustion. The last fully completed stage determined maximal aerobic power.

\section{Data Processing and Statistical analysis}

Because race distance differs depending on the age categories, all rowing performance measurements were transformed into speed (in metre per second $\langle\mathrm{m} / \mathrm{s}$ ). Before analyses were conducted, all data were coded.

Data were analysed using SPSS. The significance level was set at $=0.05$. In order to standardize speed from boats with two rowers, it was indexed. It was between 1.02 and 1.09 depending on rowers' age and boat category. The index was calculated between the winners' speed of a skiff and current boat type at last Swiss Rowing Championship (or second best if more than $10 \mathrm{~s}$ difference between the first and second one). The indexes can be obtained by contacting the authors.

\section{Boat index $=B_{i}$ Indexed boat $B_{i}$ speed $=$ boat Bi speed $\times \frac{\text { Best speed in the same boat and age category }}{\text { Best speed on a skiff in the same age category }}$}

Pearson correlation coefficient between physiological parameters and rowing performance on-ergometer and on-water were calculated. This analysis was repeated per gender with on-ergometer performance. Finally, we checked for potential confounders in the association between physiological parameters and rowing performance by comparing beta coefficients from univariable linear regression with adjusted beta coefficients when an anthropometric parameter was added, namely gender [7,10], weight and height $[1,10]$. If the difference was higher than $20 \%$, it was assumed to be a confounder.

For all rowing performances and physiological capacities, the best trial was retained for statistical analysis, data are presented in mean \pm SD.

\section{Results}

\section{Population description}

25 rowers (mean \pm SD: age $17.4 \pm 2.4$ years; height $1.78 \pm 0.07 \mathrm{~m}$; weight $69.4 \pm 8.9$; BMI $21.9 \pm 2.2 \mathrm{~kg} / \mathrm{cm} 2$ ), 6 women and 19 men were assessed. Participants competed in the following age categories: 8 in U17, 9 in U19 and 8 in senior. They had a competition experience of $4.3 \pm 2.5$ years, attended $37 \pm 27$ rowing competitions and $7 \pm 5$ ergometer competitions. Participants trained during the last month before the tests $6.7 \pm 3.4 \mathrm{~h}$ on boat, $2.3 \pm 1.9 \mathrm{~h}$ on ergometer and did during $3.1 \pm 3.9 \mathrm{~h}$ strengthening exercises with external weights and $1.5 \pm 0.8 \mathrm{~h}$ without external weights. 
Rowing performances and physiological capacities

Participants' performances and capacities per categories are presented in table 2. A significant and moderate [14] correlation of $0.66(\mathrm{p}=0.006)$ was found between on-ergometer and on-water rowing performances. Moderate to very high correlation were found between participants' physiological parameters and participants' on-ergometer rowing performance and low to moderate between participants' physiological parameters and on-water rowing performance (table 3, figure 1).

\begin{tabular}{|c|c|c|c|c|c|c|c|}
\hline \multirow{3}{*}{$\begin{array}{l}\text { Number } \\
\begin{array}{l}W=\text { Women } \\
M=\text { Men }\end{array}\end{array}$} & \multicolumn{6}{|l|}{ Capacities } & \multirow{3}{*}{$\begin{array}{l}\text { Performances } \\
\text { Best on- } \\
\text { ergometer } \\
\text { speed }\end{array}$} \\
\hline & \multicolumn{2}{|c|}{ Squat jump } & \multicolumn{2}{|c|}{ Countermovement jump } & \multirow{2}{*}{$\begin{array}{l}\text { Anaerobic } \\
\text { Mean power } \\
\text { over } 30 \text { sec }\end{array}$} & \multirow{2}{*}{$\begin{array}{l}\text { Aerobic } \\
\text { Aerobic } \\
\text { maximal } \\
\text { power }\end{array}$} & \\
\hline & $\begin{array}{l}\text { Maximal } \\
\text { strength }\end{array}$ & $\begin{array}{l}\text { Maximal } \\
\text { power }\end{array}$ & $\begin{array}{l}\text { Maximal } \\
\text { strength }\end{array}$ & $\begin{array}{l}\text { Maximal } \\
\text { power }\end{array}$ & & & \\
\hline & $\mathrm{N}$ & W & $\mathrm{N}$ & W & W & W & $\mathrm{m} / \mathrm{sec}$ \\
\hline All: 25 & $1380 \pm 216$ & $2684 \pm 535$ & $1453 \pm 226$ & $2815 \pm 595$ & $496 \pm 105$ & $302 \pm 47$ & $4.67 \pm 0.32$ \\
\hline W: 6 & $1230 \pm 91$ & $2173 \pm 204$ & $1215 \pm 130$ & $2185 \pm 191$ & $396 \pm 106$ & $253 \pm 39$ & $4.28 \pm 0.27$ \\
\hline M: 19 & $1426 \pm 224$ & $2846 \pm 505$ & $1517 \pm 214$ & $3013 \pm 536$ & $528 \pm 86$ & $318 \pm 38$ & $4.83 \pm 0.23$ \\
\hline M U17: 8 & $1361 \pm 176$ & $2672 \pm 377$ & $1515 \pm 223$ & $2880 \pm 434$ & $511 \pm 44$ & $305 \pm 37$ & $4.76 \pm 0.21$ \\
\hline M U19: 5 & $1344 \pm 291$ & $2703 \pm 627$ & $1394 \pm 291$ & $2799 \pm 632$ & $541 \pm 137$ & $316 \pm 43$ & $4.77 \pm 0.34$ \\
\hline MS: 6 & $1582 \pm 164$ & $3196 \pm 434$ & $1622 \pm 125$ & $3370 \pm 474$ & $539 \pm 88$ & $336 \pm 32$ & $4.91 \pm 0.21$ \\
\hline \multicolumn{8}{|c|}{$\begin{array}{l}\text { W: Women } \\
\text { M: Men } \\
\text { M U17: Man competing in category under } 17 \\
\text { M U19: Man competing in category under } 19 \\
\text { M S: Man competing in category senior }\end{array}$} \\
\hline
\end{tabular}




\begin{tabular}{|c|c|c|c|c|}
\hline & \multicolumn{3}{|c|}{ On-ergometer speed (in $\mathrm{m} / \mathrm{s}$ ) } & \multirow{2}{*}{$\begin{array}{l}\text { On-water speed } \\
\text { adapted per boat } \\
\text { category (in m/s) } \\
\text { All participants, } \\
\mathrm{n}=16, \mathrm{~W}: 4, \mathrm{M}: 12\end{array}$} \\
\hline & Women (W), n=6 & Men $[M], n=19$ & All participants, $n=25$ & \\
\hline $\begin{array}{l}\text { Wingate mean power } \\
\text { [in W] }\end{array}$ & $r=0.53, p=0.284$ & $r=0.71, p=0.001$ & $\begin{array}{l}r=0.78, p=0.001 \\
95 \% \mathrm{Cl}: 0.81,0.96\end{array}$ & $\begin{array}{l}r=0.60, p=0.014 \\
95 \% \mathrm{Cl}: 0.28,0.84\end{array}$ \\
\hline $\begin{array}{l}\text { Maximal aerobic power } \\
\text { [in W] }\end{array}$ & $r=0.92, p=0.010$ & $r=0.84, p=0.001$ & $\begin{array}{l}r=0.91, p=0.001 \\
95 \% \text { Cl: } 0.46,0.94\end{array}$ & $\begin{array}{l}r=0.63, p=0.009 \\
95 \% \text { Cl: } 0.19,0.86\end{array}$ \\
\hline $\begin{array}{l}\text { Squat jump max. } \\
\text { strength (in N) }\end{array}$ & $r=0.80, p=0.057$ & $r=0.73, p=0.001$ & $\begin{array}{l}r=0.74, p=0.001 \\
95 \% \mathrm{Cl}: 0.41,0.90\end{array}$ & $\begin{array}{l}r=0.54, p=0.030 \\
95 \% \mathrm{Cl}: 0.20,0.87\end{array}$ \\
\hline $\begin{array}{l}\text { Squat jump power } \\
\text { [in W] }\end{array}$ & $r=0.41, p=0.426$ & $r=0.63, p=0.004$ & $\begin{array}{l}r=0.73, p=0.001 \\
95 \% \mathrm{Cl}: 0.40,0.92\end{array}$ & $\begin{array}{l}r=0.63, p=0.009 \\
95 \% \text { Cl: } 0.32,0.85\end{array}$ \\
\hline $\begin{array}{l}\text { Countermovement jump } \\
\text { max. strength (in N) }\end{array}$ & $r=0.87, p=0.026$ & $r=0.78, p=0.001$ & $\begin{array}{l}r=0.83, p=0.001 \\
95 \% \mathrm{Cl}: 0.63,0.93\end{array}$ & $\begin{array}{l}r=0.48, p=0.062 \\
95 \% \mathrm{Cl}: 0.12,0.85\end{array}$ \\
\hline $\begin{array}{l}\text { Countermovement jump } \\
\text { max. power [in W] }\end{array}$ & $r=0.53, p=0.280$ & $r=0.55, p=0.015$ & $\begin{array}{l}r=0.72, p=0.001 \\
95 \% \mathrm{Cl}: 0.40,0.90\end{array}$ & $\begin{array}{l}r=0.64, p=0.008 \\
95 \% \mathrm{Cl}: 0.29,0.88\end{array}$ \\
\hline
\end{tabular}

Table 3: Pearson correlations from physiological parameters with rowing performance 


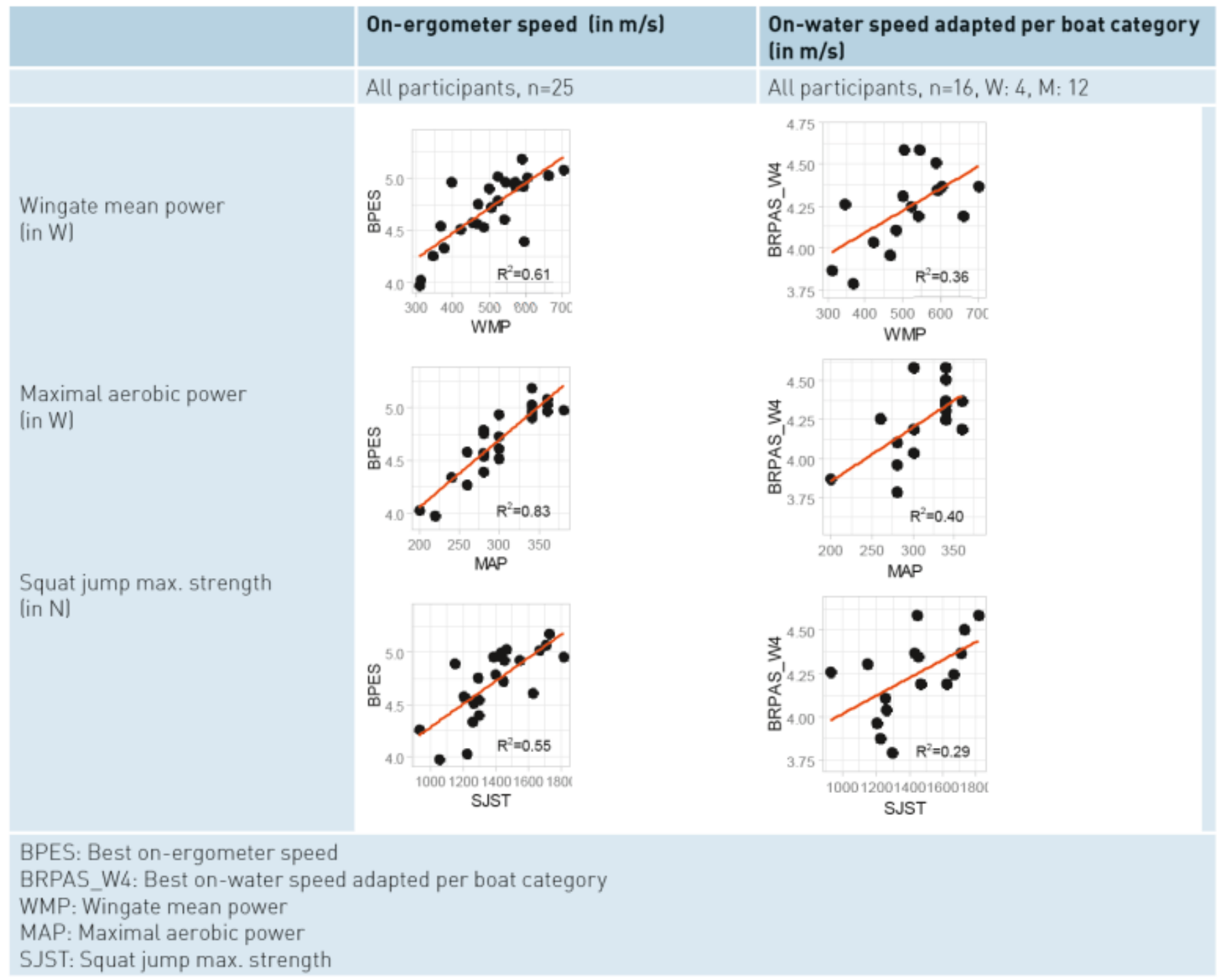

Figure 1: Scatterplotts illustrating correlations between physiological parameters and rowing performances

\section{Confounders}

Men had smaller correlation coefficient with on-ergometer performances than women for maximal aerobic power (Men: $\mathrm{r}=0.84$; Women: $\mathrm{r}=0.92$,), squat and countermovement jump maximal strength (Men: $r=0.73, r=0.78$; Women: $r=0.80, r=0.87$ ). Men had higher Wingate mean power correlation with onergometer performance than women (Men: $r=0.71$; Women: $r=0.53$ ).

Associations between physiological parameters and rowing performance were influenced by two confounders, namely weight and height. The biggest confounder between physiological parameters and on-ergometer performance was weight. Height influenced more the correlation between physiological parameters and on-water performance than the one between physiological parameters and ergometer performance (table 4). 


\begin{tabular}{|c|c|c|c|c|c|c|}
\hline & \multicolumn{3}{|c|}{ On-ergometer speed (in $\mathrm{m} / \mathrm{s}$ ) $\mathrm{n}=\mathbf{2 5}$} & \multicolumn{3}{|c|}{$\begin{array}{l}\text { On-water speed (in } \mathrm{m} / \mathrm{s} \text {, adapted per boat } \\
\text { category) } \mathrm{n}=16\end{array}$} \\
\hline & \multirow[t]{2}{*}{$\begin{array}{l}\text { Pearson correla- } \\
\text { tion coefficient }\end{array}$} & \multicolumn{2}{|c|}{$\begin{array}{l}\text { Beta standardized coefficient } \\
\text { when linear regression with }\end{array}$} & \multirow[t]{2}{*}{$\begin{array}{l}\text { Pearson correla- } \\
\text { tion coefficient }\end{array}$} & \multicolumn{2}{|c|}{$\begin{array}{l}\text { Beta standardized coefficient } \\
\text { when linear regression with }\end{array}$} \\
\hline & & Weight & Height & & Weight & Height \\
\hline $\begin{array}{l}\text { Wingate mean } \\
\text { power (in W) }\end{array}$ & $r=0.78$ & $B=0.40$ & $B=0.80$ & $r=0.60$ & $B=0.66$ & $B=0.23$ \\
\hline $\begin{array}{l}\text { Maximal aero- } \\
\text { bic power [in W] }\end{array}$ & $r=0.91$ & $B=0.64$ & $B=0.56$ & $r=0.63$ & $B=0.72$ & $B=0.26$ \\
\hline $\begin{array}{l}\text { Squat jump } \\
\text { max. strength } \\
\text { (in N) }\end{array}$ & $r=0.74$ & $B=0.22$ & $B=0.50$ & $r=0.54$ & $B=0.58$ & $B=0.26$ \\
\hline $\begin{array}{l}\text { Squat jump } \\
\text { power (in W) }\end{array}$ & $r=0.73$ & $B=0.31$ & $B=0.48$ & $r=0.63$ & $B=0.62$ & $B=0.32$ \\
\hline $\begin{array}{l}\text { Countermove- } \\
\text { ment jump max. } \\
\text { strength (in N) }\end{array}$ & $r=0.83$ & $B=0.43$ & $B=0.68$ & $r=0.48$ & $B=0.56$ & $B=0.07$ \\
\hline $\begin{array}{l}\text { Countermove- } \\
\text { ment jump max. } \\
\text { power (in W) }\end{array}$ & $r=0.72$ & $B=0.28$ & $B=0.45$ & $r=0.64$ & $B=0.66$ & $B=0.30$ \\
\hline
\end{tabular}

Table 4: Confounder analysis

\section{Discussion}

This field study identified physiological parameters which are necessary for good rowing performance. On-ergometer performance (figure 2) had the strongest correlation with aerobic capacity, followed by lower limb strength and anaerobic capacity, whereas on-water performance (figure 3) showed the highest correlation coefficient with lower limb power, followed by aerobic and anaerobic capacities.

These differences might indicate that athletes encounter different biomechanical and kinetic challenges when rowing on-ergometer than on-water. In fact, some pattern differences were already identified for the arm motion, handle force and in acceleration profiles as well as in the consistency of the stroke timing [1,15]. Nevertheless we should be careful with the interpretation of these differences as we have a rather large variability of on-water performances and large confidence intervals for the correlations measured. Thus, these findings should be confirmed and explained in future studies.

Gender seems to have an influence on the association between physiological parameters and on-ergometer performance. Indeed, aerobic capacity and lower limb strength have a higher influence on women's onergometer performance than on men's, whereas anaerobic capacity seems to play a less important role. However, the order of importance of the different physiological capacities remains the same for both genders.

These findings correspond partly to the formulated assumptions, which were that aerobic capacity would be the physiological parameter that best correlates with rowing performance followed by anaerobic capacity. They not only confirm the importance of aerobic capacity but also highlight the impact of lower limb strength and power in rowing performance.

The comparison of our results with previous literature is difficult because other studies mostly measured only on-ergometer performance, used other tests to measure physiological parameters or used a different 
population than the one described in the present article. Bourdin et al. (2004) and Ingham et al. (2002) measured aerobic capacity with a maximal aerobic power test and found significant correlation of 0.92 and 0.95, respectively with the on-ergometer performance over $2000 \mathrm{~m}$, which is consistent with the correlation of 0.91 we found. Akca [1] reported a correlation of 0.76 between lower limb maximal strength tested with a one repetition test on a leg press and on-ergometer performance over $2000 \mathrm{~m}$. Lawton et al. [15] reported a correlation of 0.69 but measured lower limb strength with a five repetition maximal strength test. This is consistent with the 0.74 we found. Regarding anaerobic capacity, previous studies found significant correlations ranking from 0.80 to 0.87 with on rowing ergometer performance over 2000 $\mathrm{m}[1,2]$ and from 0.90 over $1500 \mathrm{~m}$ [4]. Our correlation of 0.78 is a little bit lower than those presented in these studies.

Considering gender influence on the correlations, Ingham et al. [7] found smaller correlation in women than in men between aerobic (W: $r=0.91, \mathrm{M}: \mathrm{r}=0.93$ ), anaerobic power (W: $\mathrm{r}=0.74, \mathrm{M}: \mathrm{r}=0.88$ ) and onergometer performance. This is consistent with our findings for anaerobic capacity but not for aerobic capacity. Gillies and Bell [10] found stronger correlations between maximal aerobic power (W: $r=0.72, M: r=0.49$ ) and on-ergometer performance in women than in men. This finding could be confirmed in our study. However, they found lower correlations between lower limb strength and onergometer performance in women than in men (W: $r=0.29, \mathrm{M}: \mathrm{r}=0.82)$, which is not consistent with our findings. 


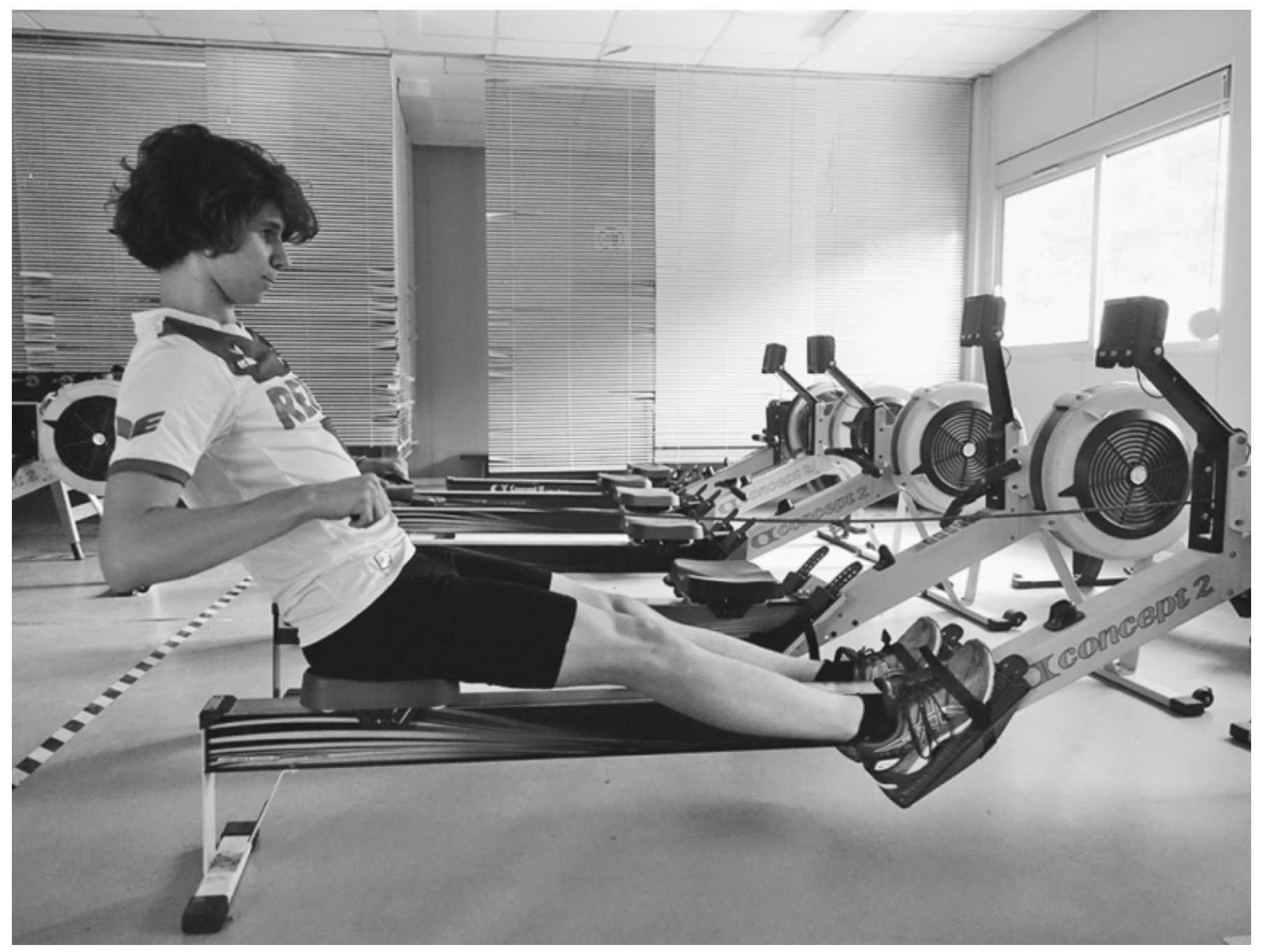

Figure 2: on-ergometer race 


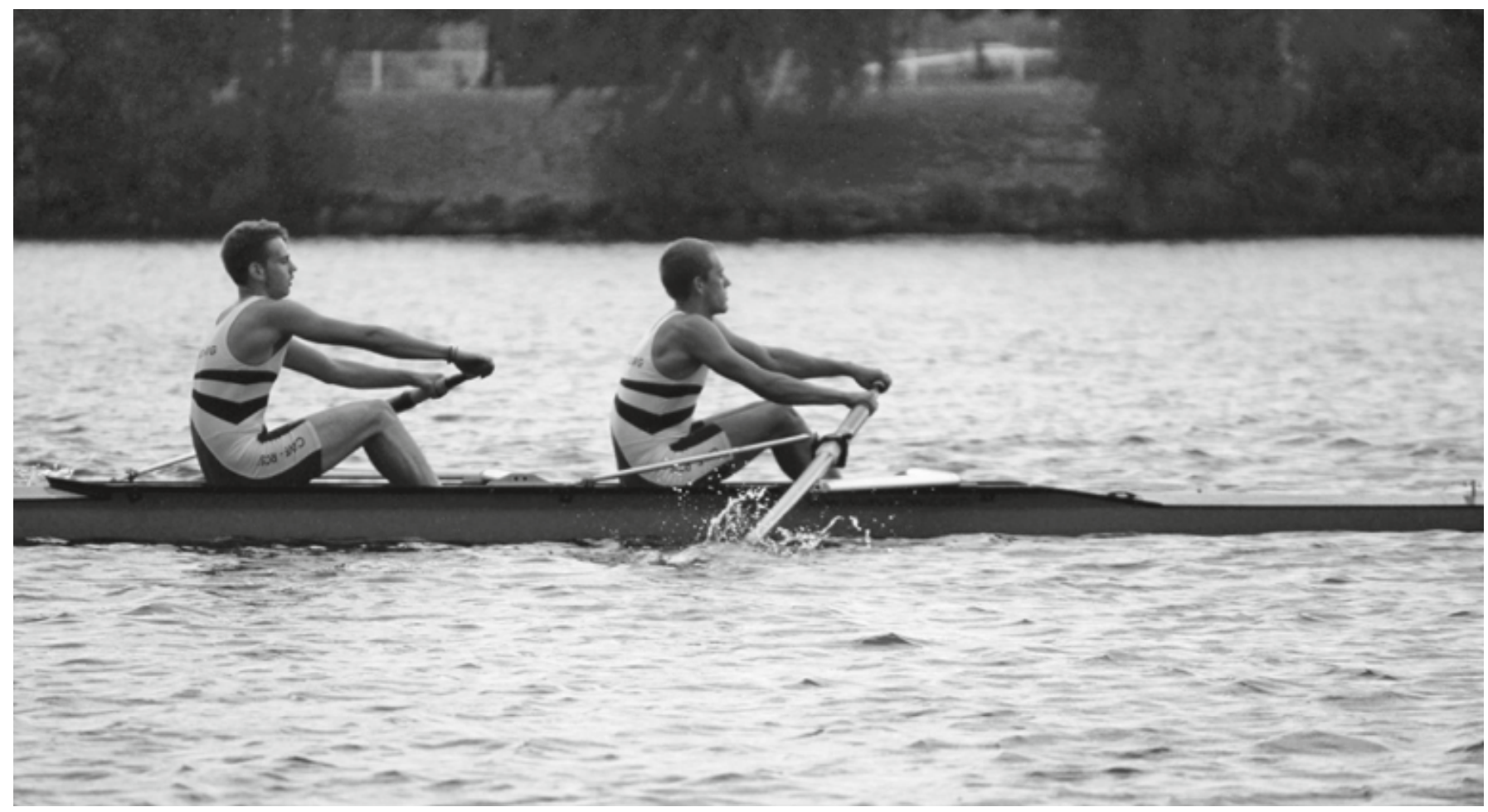

Figure 3: on-water race (Photo: Eve Augustoni)

This study is the first to assess the associations of aerobic, anaerobic and lower limb strength and power with both, on-ergometer and on-water rowing performances. It should also be noted that few studies measured lower limb strength and power during jumps as we did, despite the movement similarity with rowing. Furthermore, rowing performance was measured based on two rowing ergometer and two onwater competitions. The best result of each was retained. This is certainly more representative than the commonly used single performance in a lab condition. Indeed, the reality of the main competitions is the on-water time [5]. Finally, the variety of the sample (we include men and women from 15 to 23 years old) allows the generalisation from the results on the Swiss national level.

A main concern in our study is the time span between the tests and the competitions (maximum 3 months). It is likely that athletes had training effects during that time period. Ideally, every participant should have been tested 7 to 10 days before the competition. However, as we took the real life situation of athletes, we had to deal with competition dates and the variation in participation. Further limitations are the small sample size and the gender imbalance which do not allow giving statistically significant results per gender and age category.

Another limitation is the regeneration period between test attempts as well as between the Wingate tests and the maximal aerobic test. It is possible that the regeneration period was too short to recover from neural fatigue effects and from the digging in glycogen stocks. One could also criticize that we took the best performance for our analysis as we cannot exclude a learning effect between the attempts. The way we conducted the maximal aerobic test can be criticized as we encouraged athletes to do their best but without using maximal criteria (FC, RPE, Borg) and with a minimum duration of $4 \mathrm{~min}$. Although we considered only two competitions per rowing performance type and few rowers attended all competitions, we exceeded the typical single performance lab condition. Weather condition variability is a 
main limitation in measuring on-water performance as it has already been reported [16]. Furthermore, the use of different ergometers in different clubs induces a limitation and might have influenced the results. Another point is that only 16 rowers over the 25 participants finally compete in boots of one or two rowers and could be recorded for their on-water performances, all others compete only in boat with more than two crew members. Indeed, when we started the recruitment process, boots were not already planned. To allow a comparison between the three type of boats, namely with one rower and two types with two rowers, we used an innovative speed ratio per boat type. From a statistical point of view, it would have been better to select only boats with one rower but it would have limited the number of available participants. In case of further study, inclusion criteria should be adapted to include only rowers who planned to compete in single scull, because the assessments are done individually, or at least in boat with maximal two crew members.

\section{Implication for future research and sport practice}

The current findings help to better understand how the different physiological parameters are linked to an individual's performance. The results identified that the preparation for rowing performance should focus first on aerobic capacity and then on lower limb strength and anaerobic power for on-ergometer performance versus first on lower limb power and then on aerobic and anaerobic capacities for on-water performance. This is pretty novel knowing that on-ergometer performance is generally used to define rowing performance in previous studies and as a selection tool to identify good rowers for elite teams $[1,16]$. Our results indicate that these practices are questionable as the overall aim is always the on-water performance. Consequently coaches should be able to adjust their training protocol and get an overview of important selection criteria for members of the national elite team. Further studies with larger samples are needed to confirm these results.

It might have been interesting to further measure the sexual maturity stage and arm strength of participants. Indeed, arm strength is another parameter which might influence rowing performance in general and sexual maturity could be an important confounder in a youth sample.

\section{Conclusion}

This study provides evidence that aerobic capacity and lower limb strength are the key parameters for good rowing on-ergometer performance and that lower limb power and aerobic capacity are the key parameters for a good on-water performance. It shows that associations between physiological parameters and rowing performance depend on the competition type. Gender, height and weight should always be considered as potential confounders when analysing associations between physiological capacities and rowing performances. These findings might help to improve rower's training preparation and the selection of athletes for an elite team.

\section{Acknowledgements}

Thanks to Ilona Punt for her help with the ethical submission, to Ron Clijsen and Jan Taeymans for instructions and the loan of anthropometric measurement materials, to the team of Michaël Duc and to Patrick Flaction for the test instructions of Myotest TM, to the team of Cressy Santé for lending me the 
Myotest TM, to Myotest TM for the access to their software. Without the help and support from all of you, this study would not have been possible.

\section{First author}

Laurence Otter-Kaufmann

Dipl. physiotherapist

Bern University of Applied Sciences,

Health Division, Discipline of Physiotherapy,

Bern, Switzerland

kaufmannlaurence@gmail.com $\mathrm{c}$

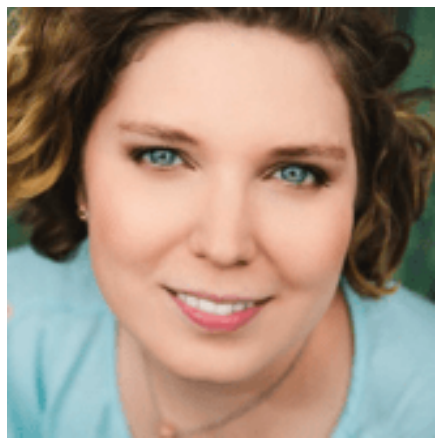

\section{References}

1. Akca F. Prediction of rowing ergometer performance from functional anaerobic power, strength and anthropometric components. J Hum Kinet. 2014;41:133-42.

2. Riechman SE, Zoeller RF, Balasekaran G, Goss FL, Robertson RJ. Prediction of $2000 \mathrm{~m}$ indoor rowing performance using a $30 \mathrm{~s}$ sprint and maximal oxygen uptake. Journal of sports sciences. 2002;20(9):681-7.

3. Bourdin M, Messonnier L, Hager J, Lacour J. Peak power output predicts rowing ergometer performance in elite male rowers. International journal of sports medicine. 2004;25(5):368-73.

4. Giroux C, Rahmani A, Chorin F, Lardy J, Maciejewski H. Specific and non specific rowing field evaluation correlated with ergometer rowing performance. 33rd International Conference on Biomecanics in Sports; Poitiers, France. 2015.

5. Smith TB, Hopkins, Will G. Measures of rowing performance. Sports Med. 2012;42(4):343-58.

6. Nevill AM, Allen S, Ingham S. Modelling the determinants of $2000 \mathrm{~m}$ rowing ergometer performance: a proportional, curvilinear allometric approach. Scandinavian journal of medicine \& science in sports. 2011;21(1):73-8.

7. Ingham SA, Whyte G, Jones K, Nevill A. Determinants of $2000 \mathrm{~m}$ rowing ergometer performance in elite rowers. European journal of applied physiology. 2002;88(3):243-6.

8. Cosgrove M, Wilson J, Watt D, Grant S. The relationship between selected physiological variables of rowers and rowing performance as determined by a $2000 \mathrm{~m}$ ergometer test. Journal of sports sciences. 1999;17(11):845-52.

9. Concept 2. VO2max Calculator 2015 [Available from: http://www.concept2.com/indoor-rowers/training/calculators/vo2max-calculator.

10. Gillies E, Bell G. The relationship of physical and physiological parameters to $2000 \mathrm{~m}$ simulated rowing performance. International journal of sports medicine. 2000;9(4):277-88.

11. Casartelli N, Müller R, Maffiuletti NA. Validity and reliability of the myotest accelerometric system for the assessment of vertical jump height. Journal of strength and conditioning research/National Strength \& Conditioning Association. 2010;24(11):3186-93.

12. Mikulic' P, Markovic G. Age-and Gender-Associated Variation in Maximal-Intensity Exercise Performance in Adolescent Rowers. International journal of sports medicine. 2011;32(5):373.

13. Tschopp M. Manuel de référence: Diagnostic de la performance d'endurance. In: Contrôle de qualité Sportmed Swiss Olympic M, editor. 2001. 
14. Hinkle DE, Wiersma W, Jurs SG. Applied statistics for the behavioral sciences. 1988.

15. Lawton TW, Cronin JB, McGuigan MR. Strength, Power, and Muscular Endurance Exercise and Elite Rowing Ergometer Performance. Journal of strength and conditioning research / National Strength \& Conditioning Association. 2013;27(7):1928-35.

16. Smith TB, Hopkins WG. Variability and predictability of finals times of elite rowers. Medicine and science in sports and exercise. 2011;43(11):2155-60. 